tion, and is delighted to know that they have a physical record of his or her child, or attention may have been drawn to some defective condition. Before the children leave school a complete physical examination ought to be made again, to determine the best vocation in life for that child.

Toronto has ninety-three public health nurses, taking up all activities in connection with the department. That includes the activities in connection with the school work. There are no school nurses or tuberculosis nurses or child welfare nurses. The public health nurse is doing the combined work. Tine school nurse, when her duties are done, so far as school is concerned, is visiting some of the homes in the district, ascertaining the conditions there. By specializing in the home rather than on the disease, the work is done much more economically and much more efficiently.

Dr. Donald B. Armstrong, Framingham, Mass., emphasized the value of using women in canvassing and covering the different sections of a community for various purposes as was done in Norfolk. Framingham made use of neighborhood committees, and in one year increased the number of registered births by nearly 30 per cent. He suggested that very frequently that type of an organization can be made a permanent organization by selecting, on various streets, the leaders, those who have the most enthusiasm, and making them a permanent group for that particular neighborhood. When called on they will attend to the distribution of literature, canvassing for medical examination, reporting of sickness as well as births, and other things. Framingham has also organized the schoolchildren into "health crusaders." This has also been tried out in other communities, and is proving very profitable. Alout 80 or 90 per cent. of the children are health crusaders. They are members of clubs in their own schools, and are helping in various ways to do different things in the community, such as sanitary inspection. This educates the youngsters and furnishes useful information. Each child keeps his own score card of public health activities and various hygienic practices that he is supposed to observe, such as hand washing before meals, sleeping a certain number of hours, etc. All of this proves to be very useful, and has interested the children so that they are now "thinking health" primarily.

Dr. J. M. Furstman, La Crosse, Wis., speaking of tuberculosis said that a combination of both the institution and nursing service would be ideal. But with the smaller communities, with 200 and 250 cases of tuberculosis and an institution accommodating. say, only forty-four cases, not much would be accomplished by hospitalization. With the general practitioner, most of the cases reported are far advanced cases. There is not any question that other members of the family have alrearly become infected. Contagious disease hospitals in the smaller communities, the speaker said, are an expensive proposition. If an arrangement could be made for some of the smaller hospitals to make an addition to the hospitals to take care of communicable diseases, the maintenance cost would be less, and more cases could be admitted. He is satisfied that we can get considerably better results for the small amount of money it is going to cost to take care of these cases in the hospitals. A hospital for communicable diseases with a bed capacity of forty would cost $\$ 50,000$. A small isolation hospital in connection with one of the hospitals gave facilities in $\mathrm{La}$ Crosse for taking care of twelve or fourteen people comfortably. This hospital has been remodeled, and now has facilities for about thirtyfive. All the expense the city has had to bear is the taking care of the patient in the hospital. There is no overhead expense; no maintenance whatever. If that system can be adopted in the smaller communities, more cases can be hospitalized.

Ascaris Escapes Through Ear.-The little girl of 4 was taken suddenly with intense earache, but there was no fever, and paracentesis brought no pus. By the third day the child had syncopes, violent nystagmus and general convulsions, and then something was seen in the ear which resembled the wormlike mass from a tube of tooth paste. It was seized with Kocher forceps and proved to be a male ascaris nearly 6 inches long.-Revue de laryngologie, 1918, 39, 358.

\section{THE ORGANIZATION OF HEALTH DEPARTMENTS}

IN CITIES OF ONE HUNDRED THOUSAND TO

FIVE HUNDRED THOUSAND POPULATION

\section{J. H. LANDIS, M.D. \\ Health Officer \\ CINCINNATI}

No hard and fast rule can be laid down for the organization of health departments for all cities of between 100,000 and 500,000 population.

Very few cities present exactly the same health problems. It follows, therefore, that while a general plan may be suggested, this plan must be flexible enough to meet varying needs due to purely local conditions.

At the present time, it would be difficult to find two cities with the same organization. Some are governed by an independent board; others are a division of some other department, such as the service or safety department; and still others are under a commissioner of health appointed by the mayor. Some have charge of hospitals, insane asylums, charitable and correctional institutions, plumbing and building inspection. In some cities, school medical inspection is a school board function, in others a health department function. Others include street cleaning and the disposal of ashes and garbage.

This lack of system leaves one practically helpless to make comparisons or to arrive at a definite conclusion as to the per capita expenditure of a given city for purely preventive medicine work.

The chaotic state in which we find the subject is probably due largely to differences in state laws and to the revolutionary political period through which American cities have been struggling. Geographic location is also of importance because of the special problems that may confront officials of coast cities or those located on or near international boundary lines. To the foregoing may be added the tremendous strides made in our knowledge of the subject of disease prevention during the past quarter of a century, and the slowness or rapidity with which this knowledge is applied.

In dealing with this subject, it is understood that nothing more than a skeleton form of organization can be outlined, and that the population to be served is to be taken into consideration in determining the number of employees working for the particular city under question.

Control by a board of experts has advantages that are hard to duplicate in any other method of organization. Among these may be mentioned a continuous policy, practically free from political interference due to changes in administration. Public health work is a highly specialized branch of medicine, requiring a vast amount of time to acquire the knowledge necessary to secure efficient results. Change in the executive officer and his force with each change in the general administration of a city results in disintegrating a trained force and substituting one inexperienced and necessarily inefficient. While incumbency is not synonymous with honesty and efficiency, the experience gained in eight years of public health work has given me a very high opinion of the honesty and efficiency of the average individual if freedom of action is assured him in the performance of his duties. Ser- 
vice under an independent board insures freedom of action to a greater degree than can be hoped for when appointment comes from some other source.

Boards of health have legislative powers and are independent of other branches of the city government in passing necessary regulations. The work of the board necessarily gives it information concerning sanitary needs and the proper method of meeting them that is impracticable for others to acquire whose time is taken up largely with other duties. In other words, it specializes in its work, knows just what it wants, and takes the most direct method in securing it.

In their recommendations for an ideal health department for Minneapolis, Biggs and Winslow say:

The administration of health laws, as in the case of most other municipal activities, should be in the hands of either a single expert or a small body of experts, in order to obtain the best results. In most city departments the single commissioner is preferable to the board. In the case of the health department, however, the framing of ordinances requires the exercise of legislative powers which can not be entrusted to a single officer. If there is a single health commissioner with no board, the ordinance framing power must be left in the council. With the complexity and rapid progress of public health science on the one hand, and the pressure of private interests on the other, such a course is certain to be disastrous. It is for this reason that whatever may be the case in other departments of government, sanitary policies and legislation and administration can be most successfully developed and carried out by a board.

The work of a department of health includes a wide variety of functions, making it necessary to group those closely related into different divisions. These, in turn, may occupy ground that is common to two or more divisions, so that the best results can be obtained only by the fullest cooperation between the various divisions. The work of the divisions of medical inspection, food inspection and the laboratory in a milk-borne epidemic of diphtheria or typhoid fever may be cited as examples of instances in which three or more divisions might be actively engaged in solving one problem.

While very few health departments perform the same functions, most of them have divisions of general administration, medical inspection, food inspection, sanitary inspection, laboratory, and vital statistics, and I shall give these divisions consideration in developing the title of this paper.

\section{GENERAL ADMINISTRATION}

To general administration belong the executive officer, the clerk and stenographers. The successful executive officer must have something in addition to a knowledge of the game to insure success; he may have a very wide knowledge of his duties and yet be a failure as an executive. Brusqueness and incivility are no longer accepted by the public as infallible signs of genius, or excused on the ground of temperament or eccentricity. He must be able to secure results and do it without creating opposition. The ability to refuse unreasonable demands and send the applicant away feeling that he has been the recipient of unusual favors is one possessed by few men, but one that is very essential to success in public health work. He must be able to harmonize the little jealousies that do so much to disorganize a force and destroy its efficiency. In a word, he must be not only a master craftsman, but he must have the personality that counts for success in any walk in life. Similar per- sonal qualities are essential for a successful clerk, for the reason that one weak link in the chain destroys the usefulness of the whole.

Publicity might well be placed in the division of general administration. The public knows what it sees, hears or reads. Where one gains knowledge by seeing or hearing, thousands learn by reading. For this reason, the activities of a department should be placed before the newspaper-reading public by some one individual in the department with special aptitude for that kind of work.

\section{FOOD INSPECTION}

The division of food inspection should employ experts only. Laymen cannot be expected to have the exact knowledge necessary for efficient work. Milk and dairy, and meat inspectors should be graduates in veterinary medicine. Since adopting this rule, Cincinnati's meat inspection service has been placed on a par with government meat inspection. The chief of the division must be familiar with all varieties of food and their multitudinous forms of adulteration. My ideal of a chief food inspector is one with this knowledge and the heart of a gladiator, for he needs that quality to place "the fear of God" in the hearts of that small minority whose rascally actions lower the tone of the entire food industry.

Food inspection should include surveillance over all foods, and the places and persons engaged in the industry, with authority to enforce regulations necessary to protect the general public from articles detrimental to health. Most forms of adulteration are commercial frauds, and their detection could very properly be assigned to some other department. It is the meat and milk supplies and other perishable foods that require constant watchfulness on the part of the food inspection division. Close cooperation with the division of infectious diseases is necessary in order that food-infected foci may be located and proper steps taken to limit the spread of infectious diseases. One or more central points for the pasteurization of milk, under supervision of the health department, would be the most important step that could be taken to minimize the spread of infection through this important article of food.

\section{MEDICAL INSPECTION}

The division of medical inspection should have as its chief an expert in the differential diagnosis of the acute infections. Medical inspection should include medical relief of the poor, surveillance over infectious diseases, the enforcement of quarantine, school medical inspection, open air schools, pure milk stations, dental inspection, epidemiologic study of the acute infections, the isolation of diseased prostitutes, prenatal and postnatal instructions, prevention of infant mortality, control of tuberculosis with special reference to the removal and detention of vicious consumptives, and control of midwives with particular attention to the prevention of blindness.

Management of hospitals, insane asylums, and correctional or charitable institutions has no place in public health work except to control the method of admitting and discharging cases of infectious disease and general sanitation of the institution.

School medical inspection should be under the control of health departments. If carried on by the board of education, twilight zones of authority are created that cripple efficiency and give rise to needless fric- 
tion. In other words, a division of authority always paves the way for inefficiency or leads to a duplication of effort and expense.

Full-time work is an absolute essential for district physicians if the best results are to be obtained and friction between the family physician and district physician is to be reduced to a minimum. Since the adoption of this policy in the Cincinnati Health Department, the work of the district physicians shows an increased efficiency of about 40 per cent., and misunderstanding with the general profession has practically disappeared. As they have no private practice, there is no ground for the suspicion that their acts may be inspired by selfish motives.

An adequate force of nurses is necessary to follow up the cases. Their influence in the home has been of the greatest importance in securing compliance with the recommendations of the district physicians.

The epidemiologic study of tuberculosis has been neglected. It is reasonable to believe that much could be learned that is now unknown concerning the spread of this disease, and the application of this knowledge would result in decreasing the morbidity and mortality rates from this cause. Every city of the first class should have one or more experts giving all their time to the study of this disease. These experts would logically be a part of the force engaged in carrying on the subdivision of tuberculosis.

The results obtained in cities devoting special attention to prenatal and postnatal instruction, to the control of ophthalmia neonatorum, and to the prevention of infant mortality, more than justify the expenditure necessary to provide the nursing and medical service.

Cincinnati's Association for the Welfare of the Blind, for example, in two years treated fifty-nine cases of "sore eyes" in new-born infants without blindness occurring in any case. This was done at an annual cost of about $\$ 1,000$ to the Association, and includes the salary and incidental expenses for a nurse. It is not to be assumed that all of these cases would have resulted in blindness had the patients received no treatment, but the chances are that many of them would have become life-long dependents from this cause. If only one was saved from this fate, the cost of prevention returns a dividend to the state for education alone of 450 per cent. Assuming that all were saved from blindness, the return on the investment amounts to 13,075 per cent., or $\$ 261,500$. The foregoing figures are very conservative, for they take no account of the blind pension and other expenses borne by public and private charity or of the economic loss due to impaired productive units.

Other figures showing the enormous economic saving brought about directly through public health work could be brought forward that would stagger the imagination.

The prevention of infant mortality means coordinating the efforts of numerous functions. Improvement in milk and water supply, the establishment of pure milk stations, the education of parents through lectures delivered to mothers' clubs, and through visiting nurses, have resulted in a reduction since 1910 in deaths from diarrheal diseases in infants under 2 years in Cincinnati from 104 to 40 per hundred thousand of population. The economic saving in eight years, assuming the potential value of an infant to be $\$ 1,000$, amounts to over a million dollars, which amount is hundreds of thousands of dollars in excess of what it cost to run the entire health department during that period. Intelligent expenditure of a small amount of money on prenatal and postnatal instruction would result in still further reducing infant deaths from preventable causes.

\section{SANITARY INSPECTION}

The division of sanitary inspection is confronted with problems of sufficient importance to require a chief who is a graduate in sanitary engineering.

As plumbing, heating, lighting and ventilating are all vital factors in determining the average state of health of a community, it seems rational to include plumbing, building, workshop, factory and tenement house inspection in this division. In Cincinnati, plumbing, building and tenement house inspection are in a subdivision of the department of public safety, while workshop and factory inspection is performed by the state. The arrangement is not a happy one for the reason that it is impossible to define accurately the line of authority separating the three departments. Work is duplicated, and not infrequently one may find three sets of orders on the same property, differing one from the other according to the personal views of the inspectors.

Close cooperation should exist between the division of sanitary inspection and accredited delegates from labor unions. In Cincinnati, the sanitarians of organized labor meet with the sanitary chief twice each month. Information concerning insanitary conditions in workshops and factories is solicited, special care being observed to suppress the source of the complaint. A vast amount of good has been accomplished, and the unions are enthusiastic in their support of the plan. The complaints are referred to the building inspector, the state inspector, or the sanitary division of the health department, according to the nature of the complaint, and the proper authority to conduct an investigation. While the work described is not ordinarily found in a health department organization, it has much to commend it to those desiring to develop latent activities in a municipality. It is a means of edusation among a class of people who are more vitally interested in securing improved sanitary conditions than any other class in the community.

In the matter of dealing with nuisances, American cities could adopt European methods with advantages in the way both of increased efficiency and economy. The regular police are charged with this duty abroad. The plan has the advantage of a large force of inspectors; regular police officers cover their beats every day, often several times each day. Orders received from a man in uniform carry more weight than those coming from the average inspection force of a sanitary division. The notion that it is beneath the dignity of a regular policeman to report conditions threatening the health of citizens is foolish and needs radical revision. He should be made responsible for sanitary conditions on his beat, as well as for the safety of life and property.

The work of the building department and that of the division of sanitation of the health department necessarily bring the two functions into close relationship. Questions concerning sanitation very naturally belong to that division; those dealing with structural defects which may have no bearing on sanitation belong to the building inspector. Lack of light and air, the presence of dampness, inadequate sewage disposal, etc., are conditions detrimental to public health and may be due to structural defects, thereby placing 
the solution of the problem in both divisions of the city government. This necessarily means a division of authority and responsibility, and calls for the closest cooperation between the two.

In Cincinnati, a vacation ordinance has done much to simplify the work of both divisions.

\section{LABORATORY}

The laboratory division calls for the full-time services of expert chemists and bacteriologists. Chemical and bacteriologic examinations of water, milk and other foods subject to infection or liable to adulterations that may directly endanger the public health are indispensable, as are facilities for the free diagnosis of specimens from cases of diphtheria, typhoid fever, tuberculosis, rabies, etc. The manufacturing of antitoxins and vaccines entails an expense that few cities are justified in assuming, and one that is better left in the control of commercial houses.

The detection of frauds practiced for purely commercial reasons and the assaying of materials used in filling public contracts, which have no bearing on public health, have no place in a department of health laboratory.

\section{VITAL STATISTICS}

The vital statistician has been called "humanity's" bookkeeper." He needs considerable in the way of tact to meet and overcome the eccentricities with which a very small minority of the medical profession burden themselves. The work includes the securing of reports and classification of births and deaths.

The reporting and classification of communicable diseases is so intimately bound up with the work of the division of medical inspection that it is included in that division of the Cincinnati health department.

\section{CONCLUSION}

In closing, it seems desirable to state that a department may have an ideal organization on paper but a very mediocre one in securing results. While a good plan is desirable, good results may be obtained in spite of the fact that the paper plan is full of defects.

In the long run, results are brought about by men who are qualified to carry out policies by a close and harmonious cooperation between chiefs of divisions and other departments of the city government. Without the proper qualifications and close cooperation, any scheme of health administration degenerates into a ghastly joke and a gruesome tragedy.

Killing Head and Body Lice.-In an article on the louse problem in the United States Army, printed in the Review of War Medicine and Surgery, October, 1918, the following thethod of killing head lice is given: Clip the hair of the head with a hair clipper and wash with a mixture of equal parts of vinegar and kerosene. This should be followed in a few hours by a bath of soap and hot water. Following this treatment a search should be made for nits and lice and if found the treatment should be repeated. For crab lice the same mixture is used, after shaving the pubic region, axillae, chest and legs. As mercurial ointment, which is sometimes used, may cause a dermatitis, yellow oxid of mercury 10 parts, salicylic acid 1 part and petrolatum 20 parts may be substituted. For body or clothes lice, heat, either dry, or, better, in the form of steam, is best. Other things suggested are the English N. C. I. powder, consisting of naphthalene 96 per cent., creosote 2 per cent. and iodoform 2 per cent. The powder is dusted over the underclothing and on the inside of the outer clothing once a week. Also crude oil 9 , soft soap 5 and water 1 part, or, soft soap 10 and crads naphthalene 90 .

\section{CEREBRAL SPASTIC PARALYSIS *}

- M. E. BLAHD, M.D.

Interim Director of Surgery, Mount Sinai Hospital AND

WALTER C. STERN, M.D.

Orthopedic Surgeon, Mount Sinai Hospital

\section{CLEVELAND}

The syndrome known as Little's disease was first brought to the attention of the profession by Little of London, who, in 1843, in a lecture before the London Orthopedic Institute, reported several cases of the disease, which since has borne his name. ${ }^{1}$ For a great number of years, this syndrome was erroneously classified as a medical entity, without any regard for the numerous causative factors. Since its etiology has been more completely recognized, it has been found that instead of its being a single medical entity, there are a great number of conditions with various etiologic factors, all producing the same end-results classified as Little's disease.

Cerebral spastic paralysis, or hemiplégie cérébrale infantile, seems a better term by which to express the manifestations of these various etiologic factors. The latter have been well classified by Grossman ${ }^{2}$ into three groups: 1. intra-uterine, or prenatal; (2) natal, or intrapartum, and (3) extra-uterine, or postnatal.

The most important prenatal factors are malformation of the brain, porencephaly, microcephalus, atrophy of one hemisphere, congenital cysts and cerebral disease. In the intrapartum etiology, the chief factors are intermeningeal hemorrhage, intercerebral hemorrhage, cerebral palsy, and degenerations of the pyramidal tract after premature delivery. Injuries to the skull with subdural hemorrhage, circumscribed encephalitis, sinus thrombosis and embolism, and syphilis constitute the chief extra-uterine causes. In order to facilitate a clearer conception of the manner in which all these enumerated factors may produce the same endresults, the physiologic pathology on which spastic paralysis is based must be studied.

Whenever there is a break in the continuity of a motor corticospinal tract, of which the pyramidal tract is the most important, there results a characteristic motor paralysis. Irrespective of whether the lesion be situated in the brain or the cord, the resulting paralysis will be the same. This paralysis consists of a paralytic and a spastic component.

\section{ETIOLOGY}

Normally, impulses are propelled along the pyramidal tract to the various muscle groups, enabling these muscles to perform certain voluntary motions; but when there is a break in some part of this tract, these impulses no longer reach the affected muscle, and they are consequently unable to carry out certain of these voluntary motions or all of them. This is termed the paralytic component. On the other hand, an involuntary spasticity of the muscles takes place, which adds itself to the actual paralysis and intensifies it. If this spasticity is examined more closely, it becomes

\footnotetext{
* From the Surgical and Orthopedic Divisions of Mt. Sinai Hospital. Cleveland.

* Read before the Section on Orthopedic Surgery at the Sixty.Ninth Annual Session of the American Medical Association, Chicago, June, 1918.

of lack of space, this article is abridged in THE Journar by the omission of the footnotes. The complete article appears in the author's reprints, a copy of which will be sent by the author on receint of a stamped, self-addressed envelop.
} 